\title{
AGENDA DA MÍDIA, DOS POLÍTICOS E DO PÚBLICO NA CAMPANHA ELEITORAL DE 2010 ${ }^{1}$
}

\author{
Emerson Urizzi Cervi \\ Michele Goulart Massuchin \\ Camilla Quesada Tavares
}

\begin{abstract}
Resumo
O paper tem por objetivo identificar os temas presentes nas agendas política, midiática e do público, observando se há relação entre o que é discutido em cada uma dessas esferas. A convergência de temas tem como ponto de partida a transferência de assuntos da agenda da mídia para a agenda do público, que posteriormente, a partir da centralidade que possuem, podem vir a ocupar espaço na agenda da elite política. Para observar como se dá esse processo analisam-se as notícias de dois jornais impressos brasileiros de abrangência nacional e o conteúdo do HGPE dos principais candidatos à presidência, no período de julho a outubro de 2010 - utilizando-se a metodologia quantitativa de análise de conteúdo - comparando-os com resultados de pesquisas de opinião pública.
\end{abstract}

Palavras-chave: Convergência; Jornais Impressos; HGPE; Opinião Pública; Agendamento.

\begin{abstract}
The paper aims to identify the themes in political agenda, media agenda and the public agenda, observing if there is convergence between what is discussed in each of these spheres. The convergence of themes as a starting point is the transfer of media items on the agenda for the public agenda, later, from the centrality they have, may come to occupy space on the agenda of the political elite. To see how this process occurs, we analyze the news of two Brazilian newspapers of national scope and the content of HGPE of presidential candidates in the period from July to October 2010 - using the methodology of quantitative content analysis - comparing this data with results of public opinion research.
\end{abstract}

Keywords: Convergence; Newspapers; HGPE; Public Opinion; Agenda-Setting.

\section{Introdução}

Segundo Aruguete (2005), o processo de agendamento é composto pela relação entre três agendas: política, pública e midiática. A agenda dos meios de comunicação depende da importância dos temas considerados mais relevantes pelos jornalistas e pelos demais níveis de influência na composição

\footnotetext{
${ }^{1}$ Este artigo faz parte dos trabalhos desenvolvidos pelos grupos de pesquisa em Comunicação Política e Opinião Pública, da UFPR, e Mídia, Política e Atores Sociais da UEPG, sendo que os dados sobre temas de primeira página e da análise do HGPE foram coletados pelos pesquisadores que integram os grupos.
} 
dessa agenda, de acordo com Shoemaker e Vos (2009); a agenda pública é composta pelos temas em que o público dá mais importância (MCCOMBS, 2009); e a agenda política consiste nas ações políticas sobre determinados temas (ARUGUETE, 2005). A proposta deste artigo é observar o que está presente nestas três agendas, sendo que a relevância do estudo está no fato de que tanto a mídia, quanto os políticos e o próprio público possuem papéis importantes no processo democrático, sendo que a sociedade se utiliza das informações provenientes da mídia para se informar a respeito dos temas de interesse público e também para avaliar a elite política. Manin (1995) e Dahl (2009), por exemplo, consideram que a presença dos meios de comunicação tem modificado o acesso dos cidadãos aos campos de poder e são atores necessários nas democracias.

Nesse cenário, a imprensa se coloca em duas perspectivas: como um espaço de agendamento das demais esferas (pública e política), mas ao mesmo tempo é o campo em que estas últimas também podem influenciar e agendar seus interesses, ou seja, são campos que se relacionam em determinados momentos, não sendo autônomos e fechados. Isso significa que, ao mesmo tempo em que a imprensa agenda o debate público, a própria agenda midiática é formada pelas interferências do público e dos políticos. Devido a esse processo circular, em que as agendas estão relacionadas e são interdependentes (SERRANO, 1999), a hipótese inicial deste trabalho é que os assuntos discutidos nesses espaços tendem a ser semelhantes.

Para identificar se essa proximidade de agendas ocorre no caso brasileiro, mais especificamente durante a campanha eleitoral de 2010, utilizam-se conteúdos que ilustram essas três esferas de debate permitindo identificar o que se destaca em cada uma delas. Para representar a agenda midiática identificam-se os temas das notícias de primeira página de dois jornais impressos brasileiros - a Folha de São Paulo e O Estado de São Paulo - por se tratarem de jornais de grande circulação e também por agendarem outros veículos menores. Para ilustrar a agenda da elite política utiliza-se, por ser um período eleitoral, o conteúdo abordado pelos principais candidatos à presidência da República no Horário Gratuito de Propaganda Eleitoral (HGPE), destinado à propaganda política e que é produzido pelos partidos políticos. E para comparar com a agenda do público, utilizam-se as pesquisas de opinião pública realizadas por institutos de pesquisas - CNT/Census e Ibope - que identificam os temas que mais preocupam os brasileiros.

Para a sistematização dos dados apresentados no paper, a metodologia utilizada é quantitativa de análise de conteúdo. Nos jornais são identificados os temas presentes na primeira página durante o período eleitoral. No HGPE são catalogados os temas e o tempo (em segundos) dedicado pelos candidatos para cada um, assim como a análise temporal durante o período de campanha. Esses dados são comparados com os temas que se destacaram em pesquisas de opinião pública realizadas em janeiro, maio e dezembro de 2010. Por fim, o artigo está dividido em duas partes. De início apresenta-se a discussão teórica sobre a construção da agenda midiática e os fatores que 
interferem nesse processo, assim como um referencial sobre o HGPE e uma breve consideração a respeito da conformação da agenda pública. Depois se apresenta a análise e discussão dos dados propostos e as considerações finais.

\section{Construção da agenda da mídia}

Nas democracias, a circulação de informação é a base para o debate e os meios de comunicação são responsáveis pela difusão de temas de interesse público. As notícias servem como suporte para debater, pois as pessoas precisam adquirir informações para pensar sobre aquilo que não faz parte da sua experiência diária. A partir do momento em que se identificou a importância que a mídia possui na sociedade, principalmente, a partir da teoria do agendamento temático (MCCOMBS e SHAW, 1972), passou-se também a dar atenção para o processo de produção do conteúdo noticioso, estudando a própria agenda midiática e as características da produção jornalística.

O mundo da vida cotidiana é a fonte de notícias para os meios de comunicação. No entanto há muitos acontecimentos para espaço e tempo muito reduzido, por isso é preciso selecionar determinados assuntos, tornando público apenas parte da realidade. Segundo Wolf (2009) o processo de produção das notícias pode ser comparado a um funil dentro do qual se colocam inúmeros dados, mas apenas alguns conseguem ser filtrados. Sendo que este processo de escolha é ainda mais hierarquizado quando se trata de definir os temas que vão ocupar a primeira página, que é o espaço mais privilegiado do jornal.

Na perspectiva de Galtung e Ruge (1965), por exemplo, havia doze fatores que explicavam o conteúdo dos jornais. Mas ressalta-se que, além de olhar para as características dos fatos, é preciso fazer escolhas sobre de que forma os temas vão aparecer no jornal. Segundo Silva (2005) é possível sistematizar os critérios de noticiabilidade em três categorias, pois há diferenças entre os valores intrínsecos aos fatos daqueles relacionados com as escolhas dos produtores. São eles: critérios de noticiabilidade na origem do fato (seleção primária/valores-notícia); critérios de noticiabilidade no tratamento dos fatos; e critérios de noticiabilidade na visão dos fatos. Todos esses estágios no processo de produção da notícia ressaltam que esta não é uma transferência fiel da realidade para os leitores e que esses critérios de escolha dão maior ou menor destaque aos acontecimentos de acordo com a forma em que ele aparece.

Dessa forma, a notícia é um produto que resulta de uma série de influências como apontam Shoemaker e Vos (2009). E além das escolhas internas relacionadas aos jornalistas, há outros fatores externos, os quais ajudam a explicar a composição da agenda da mídia. O processo de produção jornalística envolve as perspectivas do jornalista, das rotinas de produção e das políticas organizacionais, mas também há influências vindas de 
instituições externas aos meios de comunicação e do sistema social. A construção da realidade produzida pelas instituições informativas depende da postura do veículo, da sua relação com o poder político e da sua inserção na economia (ARUGUETE, 2005). Dessa forma, compreende-se que o processo de construção da notícia envolve uma série de fatores, onde se pode concluir que os assuntos que aparecem na primeira página - objeto de estudo deste artigo - são resultados de escolhas que hierarquizam estes fatos noticiados em relação aos demais.

\section{HGPE em ano eleitoral: o espaço da elite política}

Ao contrário do que acontece nos veículos de comunicação, onde os acontecimentos passam por filtros jornalísticos, como os critérios de noticiabilidade (WOLF, 2009) e os gatekeepers (PENA, 2005), no HGPE o que se tem são conteúdos exclusivamente produzidos pela elite política. Isso significa que tudo o que é veiculado naquele espaço é de responsabilidade dos partidos políticos, não sofrendo interferências externas da mídia. O horário político, como é chamado cotidianamente, é um direito de todos os partidos registrados no Tribunal Superior Eleitoral (TSE). Assim, eles têm um espaço gratuito reservado por $\operatorname{lei}^{2}$ dentro da grade de programação, tanto do rádio como da televisão.

A campanha nesses veículos é voltada para a superprodução dos programas, ou seja, é pensada a partir de todos os mecanismos comunicativos possíveis. Além disso, o HGPE tem dois papéis importantes no caso brasileiro, segundo Miguel (2004a): reduz a influência do dinheiro dos partidos e a influência das empresas de comunicação de massa no conteúdo informacional que chega até o eleitor. Os programas são pensados a partir de todos os mecanismos comunicativos possíveis.

Apesar de a legislação brasileira reservar um período na grade de programação dedicada exclusivamente à campanha eleitoral, muitos eleitores ainda não conseguem se interessar por ela. Gomes (2001) afirma que "o eleitorado não gosta das propagandas eleitorais" (p. 10), baseada numa pesquisa realizada em Porto Alegre, onde $56 \%$ dos entrevistados consideraram o HGPE de Regular a Muito Ruim. De acordo com a autora, os programas são mal feitos, não conseguindo atrair a atenção da população embora não seja isso que temos verificado nas últimas campanhas, sobretudo as presidenciais ${ }^{3}$. Gomes (2001) acredita que a campanha eleitoral deve desempenhar também uma função educativa, ou seja, contribuir com o

\footnotetext{
2 O Horário Gratuito e Propaganda Eleitoral é regulamentado através da Lei Orgânica dos Partidos Políticos, de 1995 (Lei n. 9096/95).

3 Isso porque as campanhas estão cada vez mais caras, profissionais e espetacularizadas (LAVAREDA, 2009). A receita dos partidos com os gastos de campanha movimenta milhões. Em 2010, a estimativa dos gastos do PT foi de R\$157 milhões com a campanha de Dilma Rousseff; a do PSDB foi de R $\$ 180$ milhões na candidatura de José Serra e Marina Silva previu investimento de $\mathrm{R} \$ 90$ milhões para sua campanha. Essas informações podem ser obtidas no site do TSE.
} 
crescimento do eleitor enquanto cidadão, e não apenas garantir alguns votos para determinado candidato. Isso quer dizer que as campanhas deveriam se voltar também para educar a população (GOMES, 2001). Tratando-se da televisão, essa função parece mais latente. Como é considerado o meio de maior alcance, a campanha televisiva ajudaria na conscientização política das pessoas que não têm acesso a outros meios de informação. A campanha política deveria desempenhar o mesmo papel do Jornalismo, socialmente falando: a de formar e informar o cidadão (GOMES, 2001; LAVAREDA, 2009).

No entanto, Albuquerque defende que o HGPE geralmente tem como objetivo cumprir umas destas funções: "apontar problemas sociais e apresentar sugestões para o seu solucionamento; promover a imagem do candidato, seu partido e seus aliados em termos atraentes para o eleitor; atacar adversários, candidatos ou não" (ALBUQUERQUE, 1999, p. 69). Além disso, o autor classificou as mensagens veiculadas nos programas em três categorias principais: "mensagens de campanha, de metacampanha e auxiliares" (ALBUQUERQUE, 1999, p. 69). As mensagens da campanha dizem respeito às propostas e problemas políticos, e também estão encarregadas de construir a imagem do candidato. A segunda categoria diz respeito à metacampanha. Isso quer dizer que as mensagens veiculadas se constituem de informações sobre a campanha em si - entre elas estão as pesquisas de opinião. Por fim, existem as mensagens auxiliares. Estas desempenham a função de garantir ao HGPE uma estrutura mais agradável aos olhos do telespectador, mais parecido com um programa de televisão (um telejornal, geralmente). Para isso, utiliza dois recursos: os clipes políticos (também conhecidos como jingles) e as vinhetas (ALBUQUERQUE, 1999). No caso deste paper o que mais interessa é o primeiro tipo de mensagem - as de campanha, por ser onde os temas de políticas públicas aparecem dentro dos programas.

Apesar de não ser determinante na decisão do voto, sua importância está no papel que ocupa como um dos componentes formadores do ambiente informacional dos eleitores, além de estimular o debate público sobre os temas apresentados. Oliveira (2008), ao discutir o papel do HGPE caracterizao como espaço político de apresentação de propostas e garantias ao eleitor, momento em que todos os candidatos querem mostrar-se melhor que 0 adversário para atender as demandas sociais, caracterizando-se como possível espaço público. O HGPE, segundo Veiga (2001), ocupa o local por excelência na discussão sobre a disputa travada no campo da política.

\section{A conformação da agenda pública}

A partir da teoria do agendamento, proposta ainda em 1972, a agenda do público é, em boa medida, formada a partir daquilo que é veiculado pela mídia. Parte-se do pressuposto de que os meios de comunicação são capazes de agendar os temas e seus atributos para o debate. A hipótese do agendamento atribui um papel central aos veículos noticiosos por serem 
capazes de definir itens para a agenda pública (MCCOMBS, 2009). Segundo os autores que defendem o poder de agendamento dos meios de comunicação, o público possui ou não possui informação, discute ou não discute determinados assuntos, de acordo com a relevância que esses temas ganham na mídia. A informação é a base para que os indivíduos possam formar suas opiniões a respeito dos assuntos de interesse público principalmente em períodos eleitorais, que é o momento em que decidem sobre a escolha do voto. $E$ apesar da opinião pública ser o resultado das discussões que ocorrem em espaços públicos em conjunto com outros atores, os indivíduos utilizam as informações dos meios de comunicação para posteriormente formarem suas opiniões individuais a respeito dos temas sociais e políticos e com esses parâmetros que vão discutir nos espaços em sociedade. Miguel (2004b) coloca que os leitores confiam naquilo que está sendo veiculado nos jornais ou noticiários, já que não possuem condições, eles próprios, de checar se tal fato abordado realmente ocorreu. A confirmação dessa confiança se dá pelos conteúdos similares contidos nos jornais concorrentes (MIGUEL, 2004b). Sobre isso, o autor elenca três elementos que caracterizam a crença que os leitores depositam naquilo que é veiculado nos jornais: primeiro, eles confiam na veracidade daquele fato; depois, acreditam que aquilo que está estampado nos noticiários são as questões mais relevantes daquele fato; e por fim, confiam na escolha dos jornalistas sobre os assuntos que se caracterizam como "fatos jornalísticos" (MIGUEL, 2004b). Sendo assim, a imprensa detém o monopólio da seleção dos acontecimentos que viram notícia, e que mais para frente se colocarão como sendo "a" realidade para os leitores. E já que grande parte se baseia no que é tratado nos veículos de comunicação para se informar, acaba colaborando com a conformação da opinião pública. Do mesmo, como coloca Figueiredo (2000), os políticos são dependentes da mídia porque ela é a principal preferência do público enquanto fonte de informação para tomar decisões políticas.

Os jornais focam a nossa atenção nas questões mais importantes do dia e influenciam a saliência de tópicos na agenda pública (MCCOMBS, 2009) por meio da presença nas primeiras páginas e nos formatos mais visíveis. Ao aparecerem no jornal, os temas possuem certas características (posição, espaço, elementos gráficos, etc.) que contribuem para que o público organize suas próprias agendas e possam decidir quais os temas mais importantes, sendo que, ao longo do tempo, os tópicos mais enfatizados tornam-se os mais importantes para o público, o que define o estabelecimento da agenda pública. Destaca-se ainda que o impacto da cobertura da mídia não se dá apenas na agenda do público, mas também na agenda da elite política, quando os temas possuem relação com as decisões governamentais.

No entanto, é preciso ressaltar que há outros fatores que interferem na conformação da agenda pública. Muito embora McCombs (2009) considere o tipo de cobertura mais relevante para explicar os efeitos da mídia, o autor também aponta que há fatores presentes nos indivíduos que interferem na recepção das informações - as características do ambiente informacional. 
Dessa forma, a influência dos meios de comunicação, seja nas eleições ou no agendamento de temas públicos, depende do ambiente informacional, no qual a pessoa se encontra e o seu nível de informação anterior ao conteúdo jornalístico. Assim, as predisposições, conhecimento prévio, o distanciamento dos temas, o tempo de exposição, a identidade partidária, nível de interesse e grau de informação influenciam nos efeitos que a mídia pode provocar, possuindo êxito apenas para uma parcela de indivíduos, como aponta McCombs (2009).

\section{Metodologia de análise}

Para a realização desse estudo a metodologia empregada é a quantitativa de análise de conteúdo, tanto dos jornais quanto dos programas do HGPE. O método quantitativo é o mais indicado, já que permite gerar dados estatísticos e fazer comparações a partir de generalizações (BAUER e GASKELL, 2002). A primeira página dos jornais foi escolhida como objeto de análise por ser a mais importante e possuir maior destaque na publicação ${ }^{4}$. No HGPE, optou-se por analisar todos os programas do primeiro turno dos três candidatos; e do segundo turno foram analisados os programas de Dilma Rousseff e José Serra. Assim, a coleta de ambos foi feita a partir do mesmo período, que consideramos aqui o início oficial da campanha eleitoral.

Embora os dados dos jornais não sejam do todo, a literatura nos mostra que os assuntos que merecem maior destaque estão nas primeiras páginas, pois é uma maneira de mostrar o que não se pode deixar de ler naquela edição (BEZERRA, 2005). Além de indicar as matérias mais importantes, a primeira página elenca o que deve ser prioridade e é o espaço de maior visibilidade dos jornais (ALSINA, 2009). Isso é feito através das manchetes, como aponta Bezerra (2005), e possui duas formas de hierarquização: a primeira é das manchetes no âmbito da página, que representam o maior grau de relevância daquele assunto; e a segunda é daquelas manchetes página-página, que se tornam menos relevantes conforme ocupem espaços inferiores (BEZERRA, 2005). Embora as manchetes e títulos não representem tudo o que é abordado no jornal, eles são o que os jornalistas consideram de mais importante na edição. Da mesma forma que se analisa a pesquisa de opinião pública porque esse é o espaço que materializa as prioridades do público, a primeira página representa o local onde estão os assuntos considerados mais relevantes para os jornalistas. Se a temática social não é abordada nas capas, tende-se a considerar que o jornal não acredita serem importantes os assuntos relacionados a isso para o leitor. Como a agenda da mídia envolve diversos fatores na sua construção (políticos, econômicos, mercadológicos, culturais e de interesse público), pode

4 Outro motivo é que os dados usados neste artigo fazem parte do acervo de pesquisas desenvolvidas pelo grupo de Pesquisa em Mídia Política e Atores Sociais da UEPG e pelo Núcleo de Comunicação Política e Opinião Pública da UFPR, sendo que até o momento as informações que se têm sobre periódicos são apenas da primeira página. 
ser que os meios de comunicação não reflitam os interesses expressos pelos cidadãos. Isso contribui para mostrar que outras variáveis são mais importantes na escolha dos temas do que o interesse do público, ajudando a explicar as diferenças entre as agendas da mídia e do público.

Para poder comparar as três agendas optou-se por utilizar pesquisas de opinião realizadas pelo CNT/Census e Ibope durante o ano eleitoral. As pesquisas de opinião representam as preocupações da população ao longo de todo o ano de 2010. Apesar de não expressarem a opinião dos eleitores apenas no período de campanha, as pesquisas indicam as maiores preocupações do público no ano eleitoral. Foi incluso, a título de demonstrar as mudanças ocorridas após 10 anos, dados da pesquisa de opinião pública em 1998. No entanto, a comparação entre as três agendas se fará baseada na pesquisa de 2010. Mesmo com as pesquisas em períodos diferentes do que aqueles apresentados pelo HGPE e pelos jornais, esses últimos dão conta da maior parte do período entre uma pesquisa e outra.

\section{Análise dos dados}

Os dados analisados neste tópico mostram, por meio de algumas variáveis, a presença de temas de interesse público na cobertura feita pelos jornais impressos brasileiros e nos programas eleitorais, comparando ainda com os resultados de pesquisas de opinião pública feitas durante 0 ano. 0 objetivo é identificar se há convergência entre as agendas temáticas das três esferas - midiática, política e pública - partindo do pressuposto do agendamento e da circularidade das agendas, conceitos propostos por McCombs (2009) e Aruguete (2005) para tratar da relação entre mídia, política e opinião pública. Mas destaca-se inicialmente que a proposta deste texto é verificar a similaridade entre as temáticas apresentadas e não entre as abordagens feitas sobre os assuntos nestes diferentes espaços.

Os primeiros dados, presentes na Tabela 1 , indicam quais os temas que mais apareceram no espaço de maior visibilidade dos jornais - a primeira página - durante o período de julho a outubro de 2010. Os resultados são referentes à cobertura feita pelos dois jornais de maior circulação no Brasil: Folha de S. Paulo e O Estado de São Paulo. Percebe-se que há temas que se destacam nos dois periódicos: Campanha Eleitoral, Variedades/Cultura e Economia. Estes foram os assuntos mais recorrentes em ambos os jornais, sendo que isso pode ser explicado por serem veículos concorrentes, o que leva a um agendamento entre pares, apresentando-se agendas temáticas parecidas. Como aponta McCombs (2009), os veículos se agendam entre eles e isso representa um dos níveis do processo de construção da agenda da mídia. Campanha Eleitoral é o assunto que mais apareceu, em quantidade de entradas, por se tratar de um período eleitoral. Já a presença de "Variedades" demonstra que estes jornais consideram que o entretenimento tem eficácia para chamar a atenção do leitor e "Economia" é um assunto que envolve, direta e indiretamente, o cotidiano das pessoas. Dessa forma, os assuntos 
que são mais frequentes na composição da agenda da mídia são esses, embora aqui não se tenha identificado a visibilidade (tamanho em $\mathrm{cm}^{2}$, formato e posição na página, por exemplo) que eles ocupam na primeira página.

Tabela 1 - Distribuição dos temas de primeira página durante o período eleitoral

\begin{tabular}{l|c|c|c|c}
\hline \multirow{2}{*}{ Tema } & \multicolumn{2}{c}{ Estado de São Paulo } & \multicolumn{2}{c}{ Folha de São Paulo } \\
\cline { 2 - 5 } & $\mathbf{N}$ & $\mathbf{\%}$ & $\mathbf{N}$ & \% \\
\hline Campanha eleitoral & 310 & 14,8 & 331 & 17,9 \\
\hline Político Institucional & 197 & 9,4 & 166 & 9,0 \\
\hline Economia & 284 & 13,6 & 181 & 9,8 \\
\hline Saúde & 46 & 2,2 & 88 & 4,8 \\
\hline Educação & 50 & 2,4 & 41 & 2,2 \\
\hline Atendimento/minorias & 6 & 0,3 & 15 & 0,8 \\
\hline Infraestrutura urbana & 68 & 3,2 & 79 & 4,3 \\
\hline Meio-ambiente & 57 & 2,7 & 60 & 3,2 \\
\hline Violência e Segurança & 65 & 3,1 & 95 & 5,1 \\
\hline Ético-moral & 33 & 1,6 & 61 & 3,3 \\
\hline Internacional & 123 & 5,9 & 159 & 8,6 \\
\hline Variedades/Cultura & 297 & 14,2 & 239 & 12,9 \\
\hline Esportes & 169 & 8,1 & 154 & 8,3 \\
\hline Outro & 390 & 18,6 & 182 & 9,8 \\
\hline Total & 2095 & 100,0 & & 100,0 \\
\hline
\end{tabular}

Fonte: Grupos de pesquisa UEPG/UFPR.

Estes dados mostram ainda que em razão da alta concentração nestes três assuntos, os temas sociais aparecem em quantidades reduzidas, como é o caso de "Saúde" (2,2\% e 4,8\%) e "Educação" (2,4\% e 2,2\%). Mas comparando-se os dois jornais eles aparecem mais na Folha de S. Paulo, por haver menor concentração dos três temas citados acima. Dentre os temas sociais, os que mais aparecem são "Infraestrutura Urbana" em O Estado de São Paulo, e "Violência e Segurança" na Folha de S. Paulo. De modo geral, a agenda midiática apresenta-se centralizada em determinados assuntos, sendo que os temas sociais aparecem em pouca quantidade mesmo sendo um ano eleitoral, em que tem interesse para compor o debate sobre política. Dessa forma, apesar da importância desse tipo de informação para a discussão em período eleitoral, esses assuntos não são centrais na agenda da mídia, não aparecendo com frequência e perdendo espaço para entretenimento. Assunto o qual é considerado economicamente estratégico para chamar a atenção dos eleitores que se interessam por celebridades, esporte e pessoas famosas que frequentemente compõem as notícias dessa categoria. 
Para observar as alterações da agenda da mídia, observou-se a distribuição dos temas durante o período de campanha. Agregaram-se os temas em Políticos, Econômicos, Sociais e de Entretenimento para facilitar a visualização no gráfico. O objetivo é identificar como que eles apareceram durante o período sendo que aqui a distribuição é mensal.

Gráfico 1 - Distribuição dos temas na Folha de São Paulo

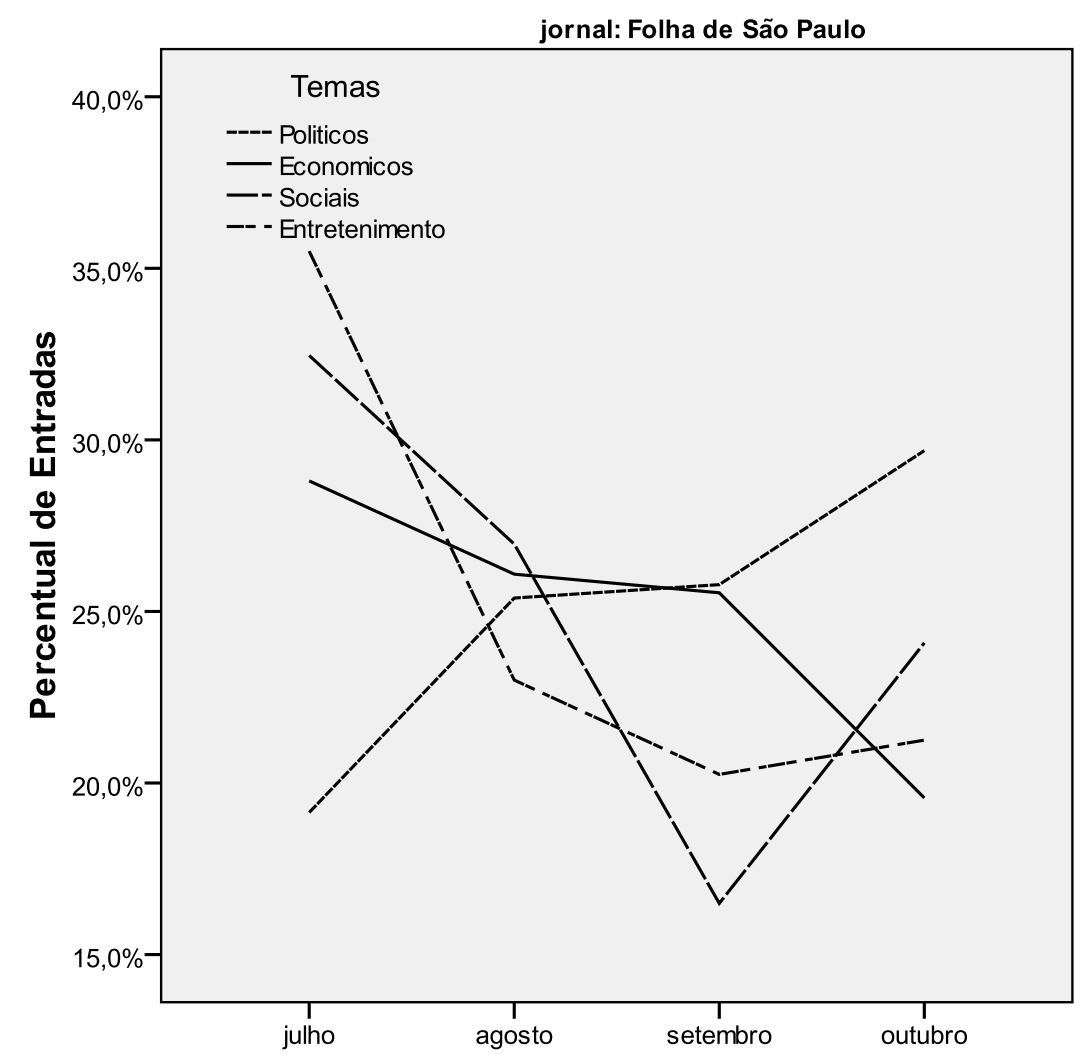

Fonte: Grupos de pesquisa UEPG/UFPR.

Nota-se, portanto, que Entretenimento e temas Sociais perdem espaço com o passar dos meses, começando com mais de $30 \%$, sendo que em outubro ficam na margem dos $20 \%$. Isso pode ser explicando pela maior presença do tema campanha política que cresce de julho a outubro, atingindo mais de $30 \%$. Embora tenha perdido espaço de julho a setembro, temas sociais voltam a ganhar um pouco mais de destaque na primeira página em outubro, com a proximidade da decisão eleitoral do segundo turno, o que é positivo para melhorar o nível informacional dos indivíduos, embora seja visível a queda se comparado com julho. Observa-se ainda a oscilação do 
tema Economia, embora apresente uma queda de quase $10 \%$ se comparado julho a outubro. O comportamento do Estadão é um pouco diferente quando se trata principalmente do tema Entretenimento e Economia.

Gráfico 2 - Distribuição dos temas no Estado de São Paulo

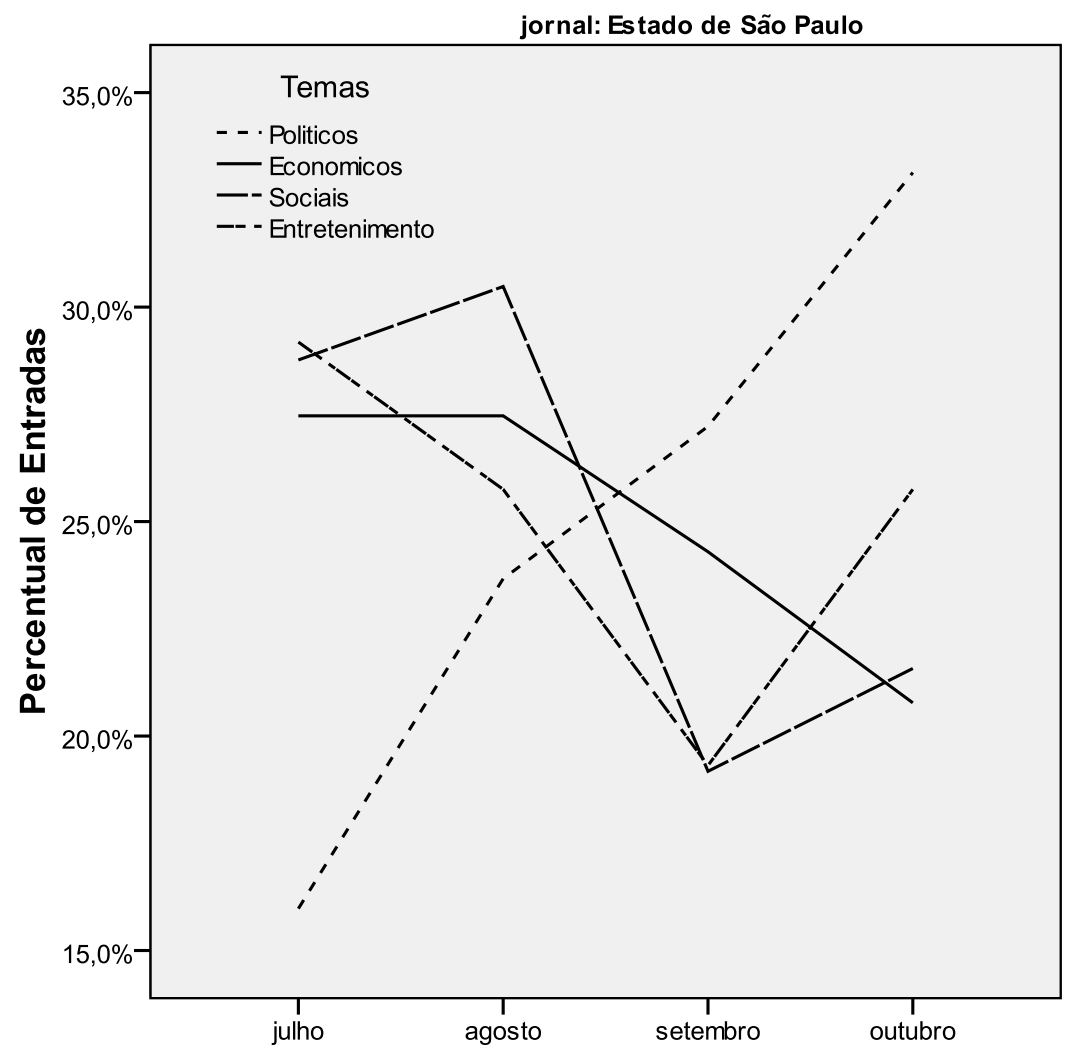

Fonte: Grupos de pesquisa UEPG/UFPR.

O gráfico aponta para a queda do tema Economia da cobertura (mas, aqui sem oscilações no período), assim como de temas Sociais e de Entretenimento. No entanto esses dois últimos voltam a subir em outubro, mas ao contrário do que ocorre na Folha de S. Paulo, em que temas Sociais aumentam mais do que Entretenimento. Já campanha cresce consideravelmente de julho a outubro, passando de pouco mais de $15 \%$ para quase $35 \%$ de entradas. De modo geral percebe-se que nestes quatro meses o interesse de ambos os jornais foi de apresentar fatos exclusivos da campanha, sendo que com isso os outros temas apresentaram queda. Mas passando o primeiro turno, percebe-se o aumento de temas Sociais para a Folha de S. Paulo e Entretenimento para o Estadão. 
Além desse espaço para propor temas, há também o HGPE. Este é um mecanismo em que a sociedade civil pode adquirir informações sobre temas sociais e observar o que a elite política considera como mais importante para compor seu plano de governo, mesmo que os temas tratados pelos candidatos sejam os mesmos e que a maior parte do programa é usada para a formação da sua imagem. Esse mecanismo informacional utilizado em períodos eleitorais é produzido pelos partidos e neste trabalho representa a agenda da esfera política. Apesar de existirem outras formas dos candidatos apresentarem suas idéias para os eleitores, o HGPE é caracterizado por não sofrer influência dos meios de comunicação e das questões econômicas como destacou Miguel (2005).

A Tabela 2, a seguir, aponta a categorização de temas que apareceram nos programas eleitorais dos três principais candidatos à presidência no pleito de 2010: Dilma Rousseff (PT), José Serra (PSDB) e Marina Silva (PV). Dessa forma é possível identificar, a partir do pressuposto da circularidade das agendas e da relação entre os campos político e midiático, se há similaridade entre os temas abordados pelos candidatos e pela mídia impressa durante o mesmo período. 
Tabela 2 - Temas presentes no HGPE dos principais candidatos à presidência

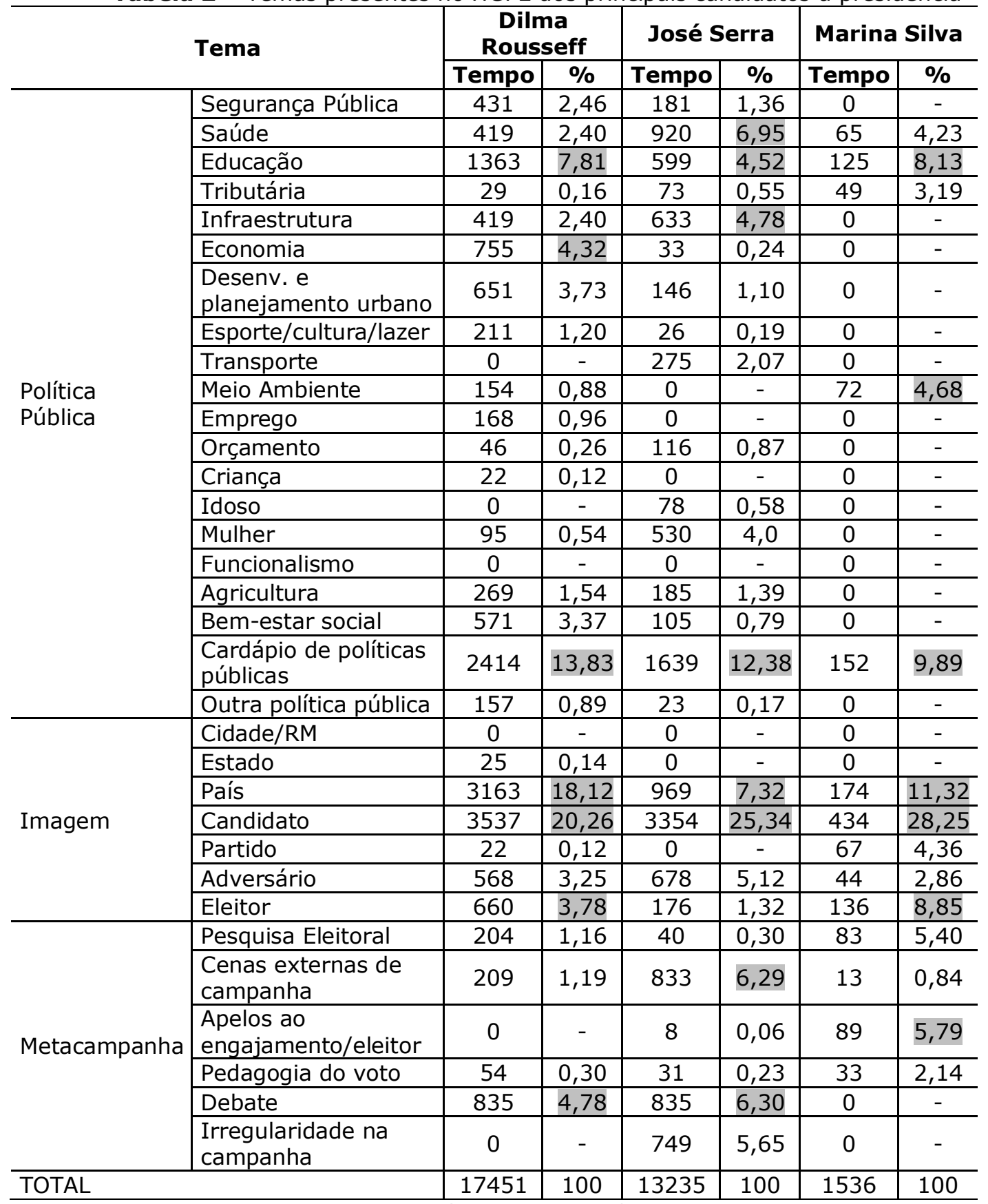

Fonte: Grupo de Pesquisa UEPG/UFPR. 
Os principais temas tratados nos programas dos três candidatos em questão variaram pouco entre si e estes utilizaram a grande parte de seus programas para promover a imagem do candidato e do país, principalmente as candidatas do PT e PV. O tempo destinado a esses temas foi bastante superior nos programas de Dilma comparado aos de Marina, consequência do tempo total que cada uma possuía no HGPE, mas os percentuais somados foram muito próximos. Já José Serra, embora também use grande parte do tempo para formação da imagem, faz uso também de metacampanha, se destacando dos demais candidatos, usando mais de 6\% para cenas externas e também para falar sobre os debates. Assim como nos jornais, os temas que interessam diretamente à população foram pouco abordados, com exceção da "Educação" e "Economia", no caso da campanha de Dilma Rousseff; "Saúde" e "Infraestrutura" nos programas de Serra; e "Educação" e "Meio Ambiente" nas falas de Marina Silva.

Nos programas da petista, a "Educação" ocupou 7,81\% e "Economia" $4,32 \%$. Destaca-se que os três candidatos usaram o "Cardápio de Políticas Públicas", onde falam de vários temas juntos, mas de forma superficial. Claro que esses números ainda são bastantes baixos se comparados ao total de tempo dos programas, mas ainda assim foram os que mais se destacaram. Os programas de José Serra (PSDB) apresentaram mais "Cardápio de Políticas Públicas" (12,38\%) e, em seguida vem o tema "Saúde" em 6,95\% do tempo total, assim como "Infraestrutura", que apareceu com 4,78\% - perto também de "Educação" com 4,52\% do tempo total. A candidata do PV, Marina Silva, apesar de estar num partido onde a principal bandeira é o meio-ambiente, fez mais menção a "Educação" e "Cardápio" do que para esta temática. Embora isso possa ser explicado pelo fato de que o assunto já conhecido como base da sua candidatura, o tema "Meio-Ambiente" apareceu em apenas 4,68\% do total do programa de Marina. A candidata também se preocupou mais com a imagem do que com os temas, assim como os demais candidatos. $O$ percentual total destinado à construção da imagem nos programas da candidata do PV foi de $28,25 \%$.

Como se pode observar, no HGPE, assim como nos jornais, os temas de políticas públicas receberam pouco destaque. E mesmo que esse espaço tenha o papel de informar o público sobre propostas dos candidatos, o que mais recebe destaque, para os três candidatos, é a formação da própria imagem. Seus programas foram encobertos por outras temáticas que não refletem na vida cotidiana do eleitor, como a "Imagem" e "Metacampanha". Dessa forma, enquanto a função do HGPE nesta campanha tem sido a formação da imagem dos três principais candidatos, o jornal tem sido espaço apenas para temas exclusivos de campanha ou para entretenimento.

E comparando o conteúdo dos jornais com o HGPE identifica-se que não há similaridade das agendas política e midiática no período, pois alguns temas púbicos (Educação, Saúde, Economia) ganharam certo destaque no HGPE, mas foram praticamente inexistentes nos jornais. Dessa forma não é possível dizer que por meio da circularidade das agendas, ocorre 
automaticamente uma transferência de temáticas entre as esferas. No entanto enfatiza-se que a campanha eleitoral se destaca na cobertura dos jornais, e o mesmo se dá no HGPE, pois os candidatos também se utilizam da metacampanha para tratar da própria campanha e até mesmo de eventos que ocorrem na esfera midiática, como é o caso dos debates. Ou seja, ao mesmo tempo em que os jornais agendam os debates e as pesquisas de opinião, 0 mesmo ocorre com os programas eleitorais, pois os candidatos tendem a comentar as pesquisas, os debates e as notícias sobre eles nos jornais. Mas em se tratando especificamente sobre os temas públicos, eles tendem a se destacar um pouco mais no discurso dos candidatos - comparando os percentuais - do que nas primeiras páginas dos jornais no período eleitoral.

Alguns desses temas apareceram ao longo de toda a campanha, mas outros foram abordados de forma esporádica como mostram os gráficos abaixo que apresentam o espaço que os assuntos ocuparam de 17 de agosto até a data das eleições para o segundo turno. Nos programas de Dilma Rousseff, a imagem do "Candidato" e do "País" ocuparam os maiores tempos frente aos outros temas e estiveram presentes durante toda a campanha, embora imagem do "Candidato" tenha maior percentual no início - quando eles se apresentam ao público - e para lembrá-los, na semana das eleições. Já imagem do "País" tem altos percentuais próximos ao primeiro turno. Já temas como "Saúde", "Educação" e "Economia" foram distribuídos irregularmente durante a campanha na televisão, como se pode verificar no gráfico 3 em que "Saúde" se concentrou em um único período no final de agosto; "Educação" aparece no início do HGPE, próximo ao primeiro turno e em pequenos períodos seguintes (começo e final de outubro). $\mathrm{O}$ mesmo ocorre com "Economia" que aparece em três momentos: programas iniciais e semana de eleições. Isso significa que além de menos tematização nos programas, essa aparição tende a ser esporádica, o que significa que poucas vezes as informações chegaram ao público neste período. Além disso, se juntar o HGPE com os jornais, há um déficit de informação para com o público: o HGPE foca na formação da imagem e os jornais centram sua produção apenas em política e variedades. 
Gráfico 3 - Distribuição dos temas ao longo do tempo no HGPE de Dilma Rousseff

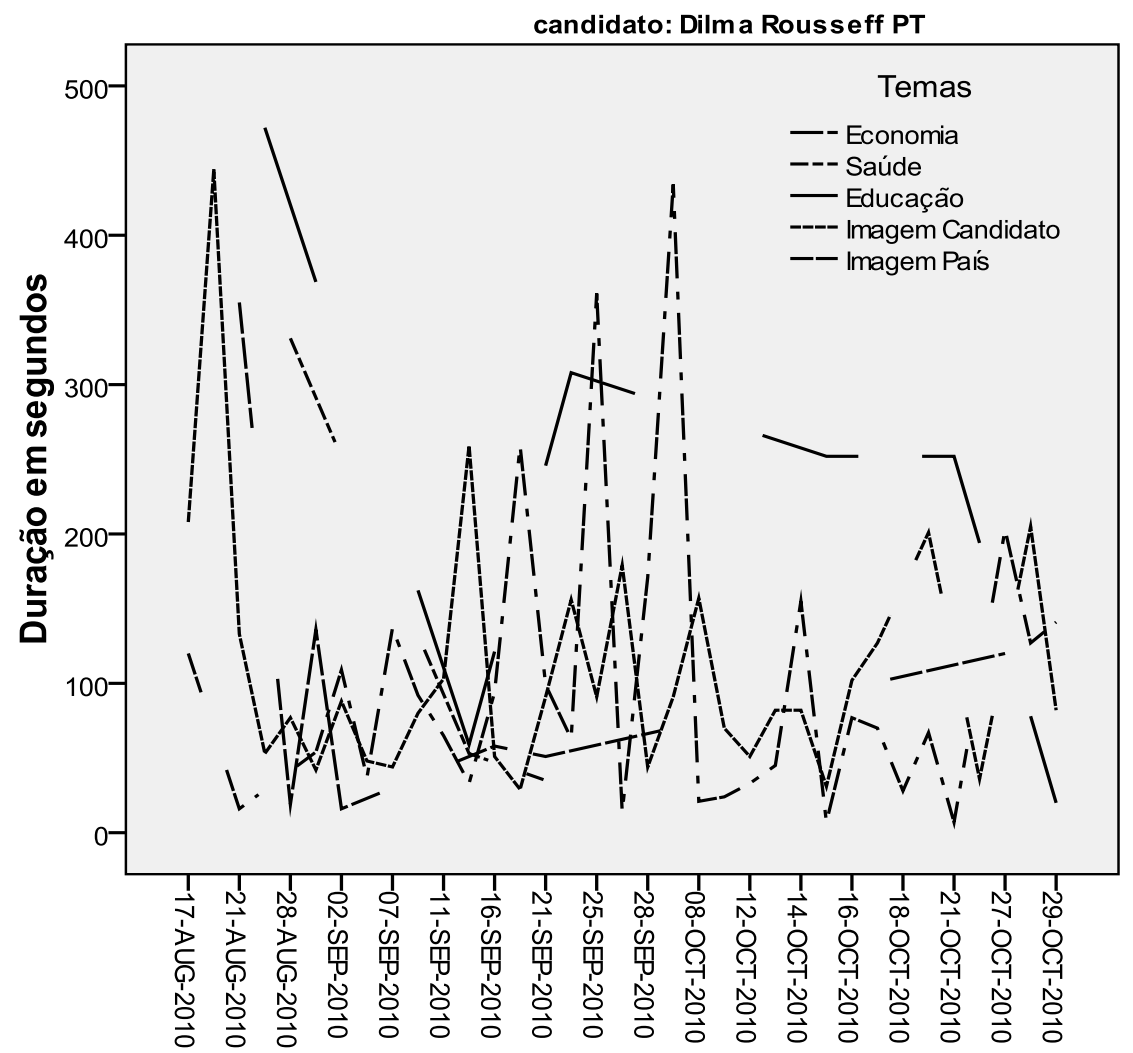

Fonte: Grupos de pesquisa UEPG/UFPR.

O Gráfico 4 mostra a distribuição dos temas, de acordo com o tempo e os dias, do candidato do PSDB, José Serra. O tema "Saúde", assim como nos programas de Dilma, apareceu em épocas isoladas, não sendo recorrentes em todos os programas e sendo foco apenas no início do HGPE, perdendo espaço no decorrer do tempo. Da mesma forma aparece segmentado o tema "Infraestrutura". O que esteve presente durante toda a campanha foi a imagem do "Candidato", embora com destaque no início e no momento que antecede as eleições. Para Serra, da mesma forma que Dilma, o objetivo do HGPE é formar a própria imagem a discutir temas públicos. Além disso, a agenda de Serra se distancia ainda mais dos jornais, pois apenas Dilma aborda "Economia" com centralidade em seus programas. 
Gráfico 4 - Distribuição dos temas ao longo do tempo no HGPE de José Serra

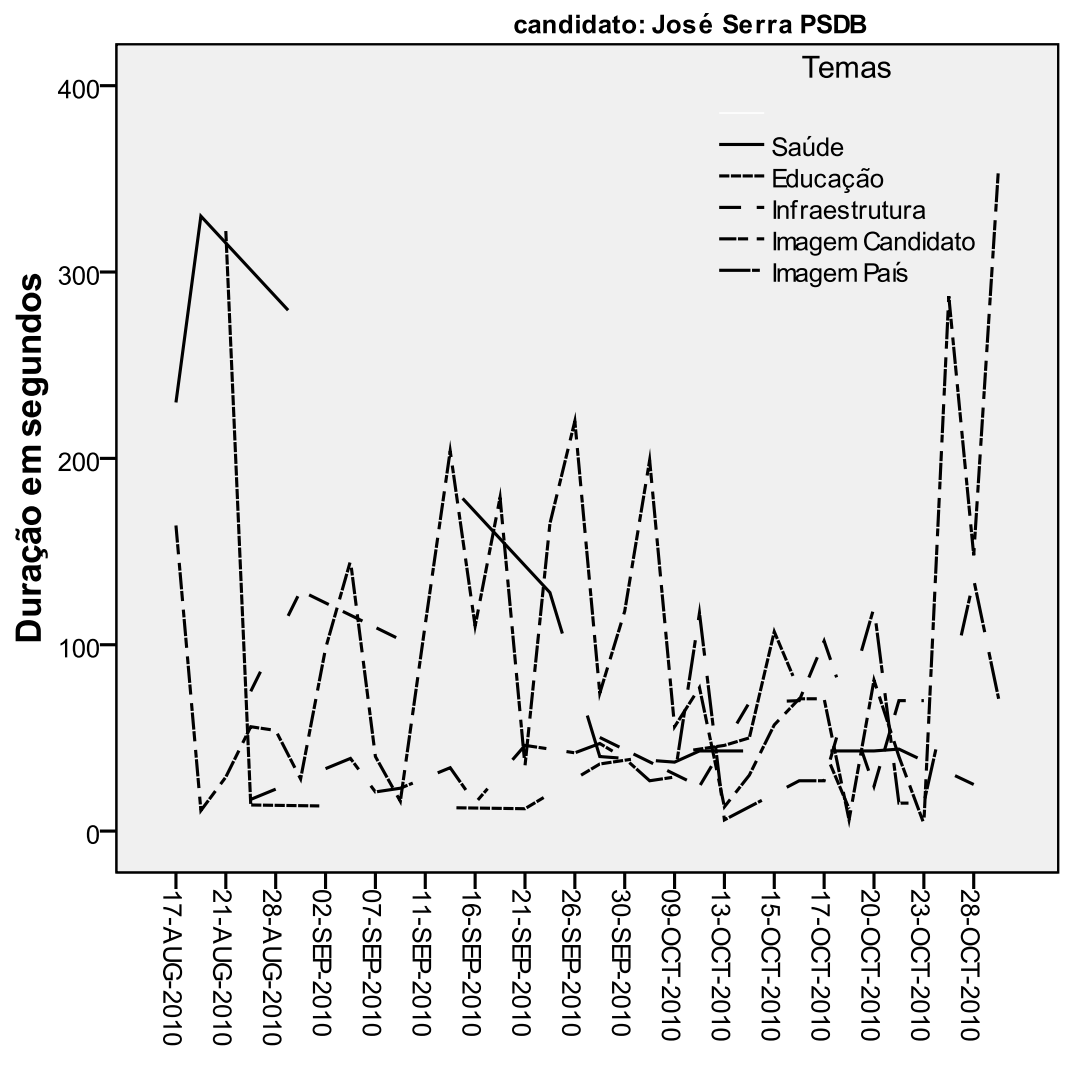

Fonte: Grupos de pesquisa UEPG/UFPR.

Por fim, a candidata do PV, Marina Silva, teve pouco tempo no HGPE, o que se torna uma limitação no momento de apresentar as propostas ao público. No entanto, como se viu anteriormente, ela não dedicou quase nada de seu tempo apresentando propostas de políticas públicas à população: apenas "Meio-ambiente" e "Educação". O que Marina Silva fez foi promover sua imagem e é isso que esteve presente na maior parte da campanha. $O$ tema "Educação" apareceu em períodos restritos, da mesma forma que "Meioambiente". A imagem do "Candidato" segue a mesma lógica dos anteriores: se apresentar ao público e se manter na memória dos eleitores, sempre. Abaixo o gráfico com os assuntos presentes nos programas da candidata do PV, Marina Silva. 
Gráfico 5 - Distribuição dos temas ao longo do tempo no HGPE de Marina Silva

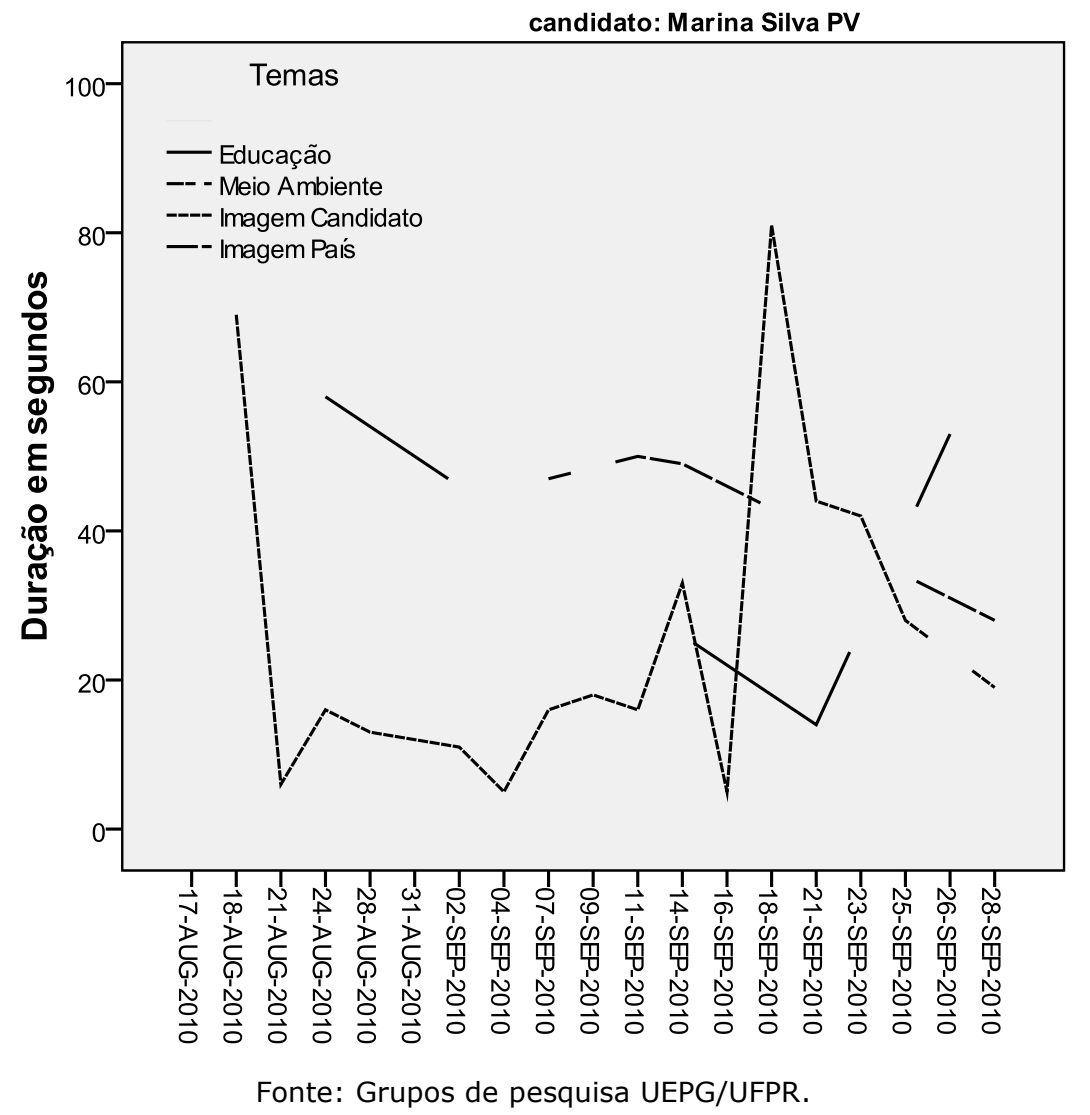

Visto como os jornais e os programas do HGPE abordaram os principais temas de políticas públicas, sem grandes similaridade, agora pretende-se verificar como o eleitor se posiciona frente a estes temas. Ou seja, observar quais são as maiores preocupações dos eleitores quanto a problemas sociais. Por meio desses dados é possível identificar se há relação entre as agendas da mídia e da esfera política com aquilo que é discutido na esfera pública. Para esses dados foram sistematizados resultados de pesquisas de opinião pública realizadas por institutos de pesquisa (CNT/Sensus e Ibope). Perguntou-se aos entrevistados qual o assunto que mais os preocupam atualmente no Brasil. Partindo-se do pressuposto que formamos nossa opinião a partir das informações que recebemos, esta questão foi respondida tendo como base o ambiente informacional de cada respondente. Dessa forma é possível identificar o tema que mais está presente no cotidiano dos indivíduos, ou seja, aquele que é lembrado ao ser perguntado sobre os assuntos que mais o preocupam. Os dados da tabela abaixo mostram os resultados para pesquisas realizadas em janeiro, maio e dezembro de 2010, 
comparando-se com resultados de 1998, que mostram as mudanças e permanências na opinião pública. Destaca-se que algumas das categorias das duas fontes de pesquisa foram reelaboradas a partir da proximidade que possuem, como é o caso de "Empregos e Salários", pois as categorias usadas pelo Ibope eram diferentes daquelas usadas pelo outros institutos de pesquisa. Embora o resultado das pesquisas seja de maio e de dezembro e a coleta do HGPE e do jornal tenha sido feita durante a campanha eleitoral, é um período intermediário, sendo que os assuntos pautados por essas duas esferas podem ter possíveis impactos nos resultados de dezembro, visto que há algumas mudanças nos dados das duas pesquisas.

Tabela 3 - Percentual de temas que mais preocupam os brasileiros

\begin{tabular}{l|c|c|c|c}
\hline \multicolumn{1}{c|}{ Tema } & mar/98 & jan/10 & $\mathbf{m a i} / \mathbf{1 0}$ & $\mathbf{d e z / 1 0}$ \\
\hline Saúde Pública & 8 & 6,7 & 41 & 46 \\
\hline Economia/Impostos & 5 & 9,6 & 4 & - \\
\hline Educação & 2 & 2,2 & 7 & 19,5 \\
\hline Violência/Segurança/Drogas & 13 & 44,1 & 21 & 15,1 \\
\hline Empregos/Salário & 66 & 27 & 7 & 9,2 \\
\hline Habitação/Trânsito & - & 0,8 & 2 & 3,1 \\
\hline Transporte/Saneamento/Infraestrutura & 1 & 1,2 & 1 & 4,8 \\
\hline Fome/Miséria/Pobreza & 3 & 5,4 & 6 & - \\
\hline Aposentados & 2 & 2,4 & 2 & - \\
\hline Corrupção & - & - & 5 & - \\
\hline Nenhum/Outro & - & 0,5 & 4 & - \\
\hline NS/NR & - & 0,5 & - & 1,8 \\
\hline Total & 100 & 100 & 100 & 100 \\
\hline
\end{tabular}

Fonte: CNT/Sensus (mar/98; jan/10; dez/10) e IBOPE (mai/10).

De acordo com a tabela, percebe-se que a opinião das pessoas se alterou ao longo do tempo, principalmente no decorrer de 2010. "Saúde Pública" passou a ganhar destaque na opinião pública a partir de maio, com $41 \%$ das respostas e $46 \%$ em dezembro. Já "Economia" perde espaço no decorrer dos meses, desaparecendo na última pesquisa. Sobre "Educação" percebe-se aumento na preocupação dos brasileiros, enquanto identifica-se queda quanto a "Violência e Segurança" e também no que diz respeito a "Emprego/Salário". Os demais temas, apesar de citados nas pesquisas, aparecem com percentuais bastante baixos. De modo geral aumentou a preocupação do público com "Saúde" e "Educação" e diminuiu a atenção para "Emprego/Salário", "Violência" e "Economia".

O gráfico 6 mostra a oscilação dos principais temas ao longo do período de 2010, de acordo com as pesquisas realizadas durante o ano, o que demonstra a oscilação da opinião dos indivíduos a respeito de determinados assuntos durante o período de 2010, principalmente se relacionada com 1998 - ponto número 1 do gráfico. 
Gráfico 6 - Temas que mais incomodam o brasileiro ao longo do tempo

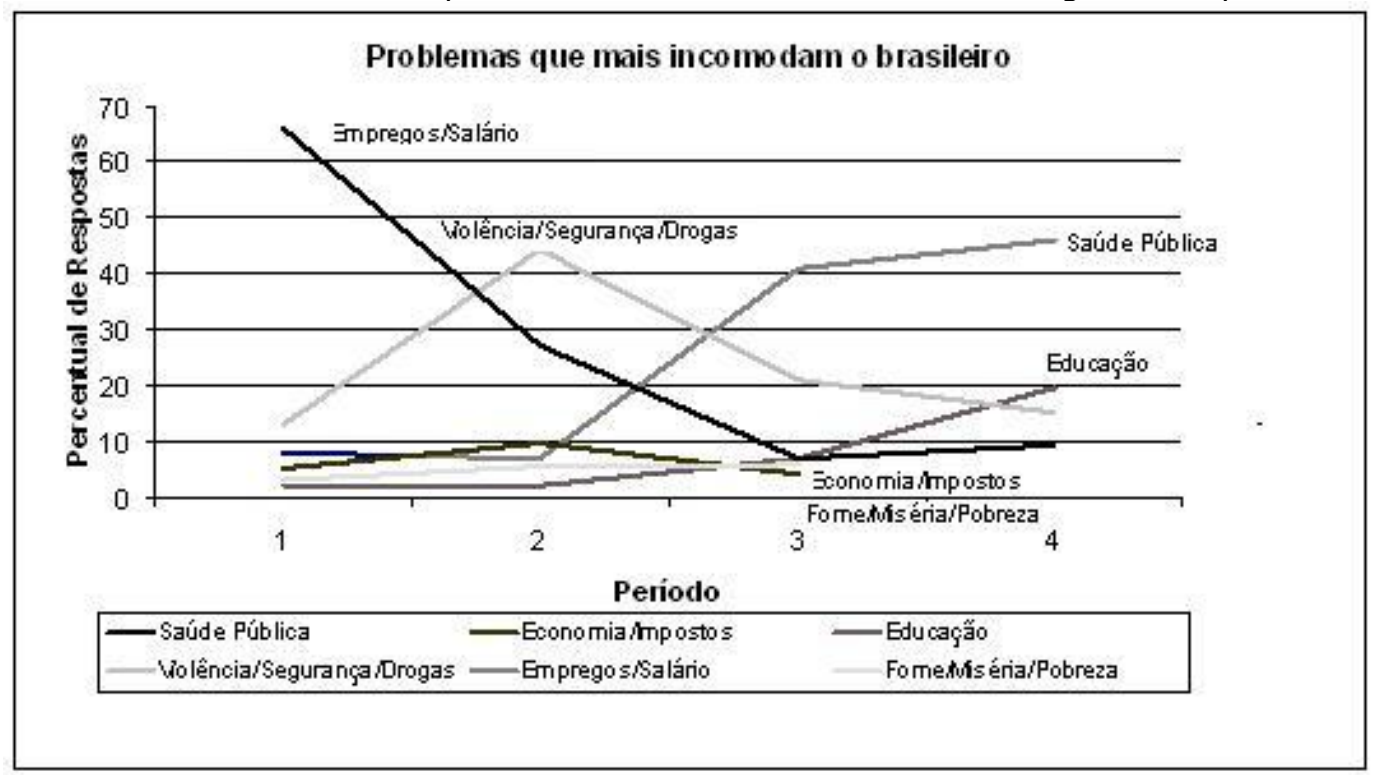

Fonte: Ibope e Census/CNT.

Essas mudanças na opinião podem ser comparadas com a agenda de temas da mídia e também do HGPE, observando se pode ter ocorrido algum impacto a partir das informações que os cidadãos receberam durante o período eleitoral. Mas se analisados os assuntos que mais aparecem na mídia no período de julho a outubro de 2010, não é possível identificar relação entre as duas agendas: da mídia e do público. Neste caso, apenas observando a tematização, não houve transferência de assuntos dos jornais para o público, já que os temas que mais aparecem na opinião da sociedade não são os que mais aparecem no jornal. No jornal, como apontado no início, destaca-se "Economia", "Política" e "Entretenimento", diferente do que se observou na opinião pública. "Economia", por exemplo, embora apareça bastante no jornal, não é tida como uma preocupação pelos brasileiros. No entanto, destaca-se que isso também está relacionado com a situação econômica do país que tem mais impacto do que frequência de temas sobre o assunto na mídia. Já "Violência/Segurança", que aparece nos jornais com maiores percentuais entre os temas sociais, não aparece no HGPE (segurança pública) e não teve impacto na opinião das pessoas, já que se observou queda na preocupação com esse assunto, se comparado com janeiro de 2010.

Embora não observadas similaridades entre as agendas da mídia e do público, percebe-se que há mais relação entre os temas que os políticos mais tratam nos programas eleitorais com aqueles que mais se destacam nas preocupações dos brasileiros. Dessa forma é possível identificar alguma similaridade entre os temas da agenda política e da agenda pública, pois os 
eleitores podem assistir o HGPE e posteriormente discutir sobre os temas ali abordados, formando suas opiniões. Além disso, os políticos tendem a dar atenção àqueles temas que mais preocupam e chamam a atenção do público, utilizando essa convergência de agenda como estratégia de campanha, já que em maio a pesquisa já mostrava alto percentual para o tema "Saúde", por exemplo. Destaca-se que "Educação" foi o assunto que mais se destacou nos programas e também é o segundo que mais preocupa os brasileiros. Além disso, "Saúde" também aparece nos programas dos três candidatos e é o mais citado pelos respondentes da pesquisa, com $41 \%$ em maio e $46 \%$ em dezembro.

\section{Considerações finais}

Ao final da análise a hipótese inicial não foi totalmente comprovada, já que os assuntos tratados nas três agendas - pública, política e midiática não foram convergentes em sua maioria, ou seja, os temas considerados mais importantes para estas três esferas são diferentes. Observou-se que nos jornais o que ganhou mais destaque foram as notícias sobre "Campanha Eleitoral", "Variedades/Cultura" e "Economia". Apesar da importância do tema campanha política neste período, já que os meios de comunicação representam as principais fontes de informação (ARRUGUETE, 2005), destacase que os temas de interesse público, para além das eleições presidenciais, não ganharam destaque na primeira página.

E embora "Economia" seja um tema recorrente nos jornais, isso não se reflete nas preocupações do público. Quando se compara a agenda midiática com a agenda pública, através das pesquisas de opinião, verifica-se que o tema não foi sequer citado pelos cidadãos em dezembro de 2010, sendo que o assunto que mais ganhou destaque na opinião dos indivíduos ao longo do ano eleitoral de 2010 foi "Saúde Pública". E este, embora apareça como a maior preocupação dos indivíduos, esteve muito pouco presente na cobertura feita pelos jornais $(2,2 \%$ na Folha de S. Paulo e $4,8 \%$ no Estado de São Paulo). Esses dados iniciais mostram que não há grande similaridade entre as agendas dos jornais estudados com aquilo que o público considera mais preocupante. Dessa forma, neste caso específico, não é possível dizer que há relação direta de temas a partir do processo de agendamento, como propõe McCombs e Shaw (1972).

Já quando comparados os programas eleitorais, percebe-se que há algumas similaridades, mesmo que esse espaço tenha sido usado majoritariamente para formação da imagem dos candidatos. Os temas "Economia", "Educação", "Saúde" e "Infraestrutura" foram os mais citados dentre os programas dos três principais candidatos. Contudo, eles ainda foram pouco retratados se relacionados à formação da imagem do candidato, que ocupou mais de $20 \%$ do espaço nos programas dos três candidatos aqui estudados. Sobre os temas que mais apareceram, destaca-se "Educação" nos programas de Dilma e Marina, com $7,81 \%$ e $8,13 \%$ respectivamente; e 
"Saúde", nos programas de José Serra, com 6,95\%. Ao comparar a agenda pública - a partir destes dados - com a agenda política, encontra-se alguma similaridade entre o que é importante para o público e o que é retratado no HGPE, representando aquilo que a elite política considera mais relevante. Isso porque, como se pode constatar no Gráfico 6 (ver gráfico), a preocupação com "Educação" e "Saúde Pública" aumentou com o passar dos meses, e esses foram os temas mais recorrentes nos programas do HGPE dos candidatos estudados neste artigo.

No entanto, não se identificou relação de proximidade entre os temas abordados pela mídia e a agenda dos políticos no período eleitoral de 2010, o que condiz com uma pesquisa feita em eleições anteriores, em que apenas em 1989 foi possível identificar pautas do HGPE interferindo na agenda de telejornais (MIGUEL, 2004a). A presença de temas públicos nas duas agendas é pequena, mas no caso dos jornais a cobertura foca na agenda diária e fatos exclusivos de campanha, enquanto os políticos ressaltam a formação da sua imagem pública. Isso também mostra que embora diversos autores considerem que essas esferas estão em constante relação, isso não se traduz na relação de temas e assuntos presentes nesses dois ambientes. E mesmo que o HGPE não tenha alterado a agenda da mídia, isso não significou irrelevância na sua construção da agenda pública (MIGUEL, 2004a), já que alguns temas do HGPE estiveram presentes nas respostas dadas pelos respondentes da pesquisa.

Apesar das relações entre os temas mais citados pelo público com aqueles mais presentes no HGPE, destaca-se que pode haver outros fatores que influenciaram nessa percepção do público - amigos, colegas de trabalho, convivência, nível educacional, proximidade com o assunto, etc. - o que chamamos de ambiente informacional. Dessa forma, apesar de identificar certa similaridade entre as agendas do público e do HGPE, não é possível dizer que essa proximidade seja exclusivamente resultado desse processo, pois há muitos outros fatores que influenciam na formação da opinião. Chama-se atenção também para algumas limitações geradas pelos dados na pesquisa. Embora seja possível identificar alguma proximidade entre o HGPE e a agenda pública, e uma distância maior dessas esferas com aquilo que é considerado mais importante pela grande mídia brasileira, não se trabalhou com o jornal todo e as pesquisas de opinião pública não foram acompanhadas semanalmente, sendo um resultado agregado de todo o período. No entanto, as considerações aqui apresentadas mostram, mesmo com essas limitações metodológicas, divergências entre aquilo que as esferas consideram mais importante: os jornais focam a atenção para a campanha política e entretenimento, O HGPE foi usado para formar a imagem dos candidatos e o público se preocupou com temas que estiveram pouco presentes na agenda da mídia e mais no HGPE.

Emerson Urizzi Cervi é Doutor em Ciência Política pelo Instituto Universitário de Pesquisas do Rio de Janeiro (IUPERJ), professor adjunto do Departamento 
de Ciências Sociais e do Mestrado em Ciência Política da Universidade Federal do Paraná (UFPR) e do Departamento de Comunicação/Jornalismo da Universidade Estadual de Ponta Grossa (UEPG).

E-mail: ecervi7@gmail.com

Michele Goulart Massuchin é Bacharel em Comunicação Social - Jornalismo pela Universidade Estadual de Ponta Grossa (UEPG) e mestranda em Ciência Política pela Universidade Federal do Paraná (UFPR). Membro do grupo de Pesquisa em Comunicação Política da UFPR/UEPG e bolsista REUNI.

E-mail: mimassuchin@hotmail.com.

Camilla Quesada Tavares é Bacharel em Comunicação Social - Jornalismo pela Universidade Estadual de Ponta Grossa (UEPG) e mestranda do Programa de Pós-Graduação em Ciências Sociais Aplicadas também pela UEPG. Bolsista CAPES.

E-mail: camilla.tavares8@gmail.com

\section{Referências}

ALBUQUERQUE, Afonso de. Aqui você vê a verdade na tevê - A propaganda política na televisão. 1999. 204 f. Dissertação (Mestrado em Comunicação, Imagem e Informação) - Programa de Pós-Graduação em Comunicação, UFF, Niterói, 1999.

ALSINA, Miguel. A Construção da Notícia. Petrópolis: Vozes, 2009.

ARUGUETE, Natália. Los medios de comunicación y la formación de la agenda pública. Verso e Reverso - Revista de Comunicação, São Leopoldo, v. 19, n. 41, 2005. Disponível em: <http://www.unisinos.br/_diversos/revistas/versoe reverso/index. php?e $=5 \& s=9 \& a=46>$. Acesso em: 20 set. 2011 .

BAUER, Martin W.; GASKELL, George. Pesquisa qualitativa com texto imagem e som: um manual prático. Petrópolis: Vozes, 2002.

BEZERRA, Heloísa Dias. Cobertura Jornalística e Eleições Majoritárias: Proposta de um modelo analítico. 2005. 331 f. Tese (Doutorado em Ciência Política) - IUPERJ, Rio de Janeiro, 2005.

DAHL, Robert. Sobre a Democracia. Brasília: Ed. UnB, 2009.

FIGUEIREDO, Marcus. Mídia, Mercado de Informação e Opinião Pública. In: GUIMARÃES, César; JUNIOR, Chico (Orgs.). Informação e Democracia. Rio de Janeiro: Ed. UERJ, 2000. p. 38-46. 
GALTUNG, Johan; RUGE, Mari Halmboe. The structure of foreign news: The Presentation of the Congo, Cuba and Cyprus Crises in Four Norwegian Newspapers. Journal of International Peace Research, Oslo, v. 2, n. 1, p. 6490, mar. 1965.

GOMES, Neusa Demartini. Formas persuasivas de comunicação política. Porto Alegre: EDIPUCRS, 2001.

LAVAREDA, Antônio. Emoções Ocultas e Estratégias Eleitorais. Rio de Janeiro: Objetiva, 2009.

MANIN, Bernard. As metamorfoses do governo representativo. Revista Brasileira de Ciências Sociais, São Paulo, v. 10, n. 29, p. 1-34, out. 1995.

MCCOMBS, Maxwell. A Teoria da agenda: a mídia e a opinião pública. Petrópolis: Vozes, 2009.

MCCOMBS, Maxwell; SHAW, Donald. The Agenda-Setting Function of Mass Media. Public Opinion Quarterly, Oxford, v. 36, n. 2, p. 176-187, summer 1972.

MIGUEL, Luís Felipe. Discursos cruzados: telenoticiários, HPEG e a construção da agenda eleitoral. Sociologias, Porto Alegre, s/v., n. 11, p. 238-258, jun. 2004a.

. Mídia e vínculo eleitoral: a literatura internacional e o caso brasileiro. Opinião Pública, Campinas, v. 10, n. 1, p. 91-111, maio 2004b.

. Televisão e construção da agenda eleitoral no Brasil. Diálogos Latioamericanos, México, v. 1, n. 10, p. 1-16, jan. 2005.

OLIVEIRA, Christine. Horário Gratuito Político Eleitoral - HGPE: O eleitor e a cidadania política. 2008. 368 f. Tese (Doutorado em Comunicação Social) Programa de Pós-Graduação em Comunicação Social, PUCRS, Porto Alegre, 2008.

PENA, Felipe. Teoria do Jornalismo. São Paulo: Contexto, 2005.

SERRANO, Estrela. Jornalismo e elites do poder. 1999. Disponível em: <http://www.bocc.ubi.pt/pag/serrano-estrela-jornalismo-elites-poder.pdf>. Acesso em: 29 set. 2011.

SHOEMAKER, Pamela J.; VOS, Timothy. Gatekeeping Theory. New York: Routledge, 2009. 
SILVA, Gislene. Para pensar critérios de noticiabilidade. Estudos em Jornalismo e Mídia, Florianópolis, v. 2, n. 1, p. 95-107, I sem. 2005.

VEIGA, Luciana Fernandes. Em Busca de Razões para o Voto: o uso que o homem comum faz do Horário Eleitoral. 2001. 246 f. Tese (Doutorado em Ciência Política) - IUPERJ, Rio de Janeiro, 2001.

WOLF, Mauro. Teorias da comunicação. Lisboa: Presença, 2009.

Texto recebido em 08/08/2011.

Aprovado em 22/12/2011. 